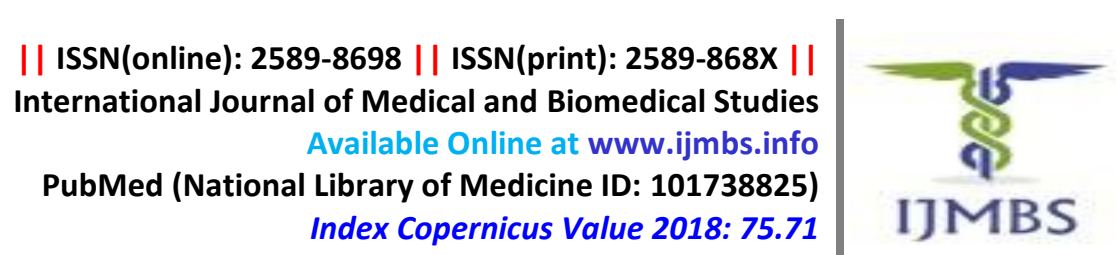

Original Research Article

Volume 4, Issue 2; February: 2020; Page No. 227-231

\title{
STUDY OF DORSAL SACRAL TRIANGLE IN HUMAN SACRA
}

\section{Dr. Manoj Bhavanidatta Joshi}

Associate Professor, Dept. of Anatomy, Saraswati Medical College, Unnao, U.P.

Article Info: Received 02 January 2020; Accepted 02 February 2020

DOI: https://doi.org/10.32553/ijmbs.v4i2.981

Corresponding author: Dr. Manoj Bhavanidatta Joshi

Conflict of interest: No conflict of interest.

\author{
Abstract \\ Introduction:
}

Sacrum is a triangular bone shaped by combination of five sacral vertebrae. It is embedded as a wedge between the two innominate bones at the upper and back portion of pelvic bone. The opening show at the caudal conclusion of sacral canal is known as sacral rest. It is shaped due to the disappointment of combination of laminae of the fifth (every so often 4th) sacral vertebra. It is situated inferior to the 4th (or $3 \mathrm{rd}$ ) fused sacral spines or lower end of median sacral crest. Sacrum is a vital bone for recognizable proof of sex in human skeletal framework. Since it may be a component of hub skeleton and and pelvic support, it has an applied significance in deciding sexual orientation with the assistance of estimation carried upon it. The well- known strategy for assurance of male and female sacra has been the Sacral file (SI). The varieties within the structure of dorsal divider of sacral canal are various. It may be open all through its whole length or there may be moo lying lamina of to begin with sacral vertebra. Other varieties incorporate lacks between its predominant and second rate limits, pulverization of lumen of sacral canal and hard abundance annihilating the break. The nearness of any gaps may allow the needle to elude the canal coming about in subcutaneous statement of anesthetic operator. The sacral hiatus has been used for administration of caudal epidural anesthesia in obstetrics as well as orthopedic practice for treatment and diagnosis. The foremost visit issue experienced in caudal epidural square is needle situation as in some cases it is troublesome to decide the anatomical area of sacral rest particularly in grown-ups. Clinical assessment of needle arrangement can be done with ultrasonography or fluoroscopy. In any case, it isn't continuously doable to do so since of time and cost limitations. Varieties have been found within the shape and level of sacral break. Anatomical points of interest and the information of real shape and size of sacral rest and its varieties play a major part within the victory of needle situation.

Aim: The main of this study is to find out the anatomical variations of sacral hiatus of the cadaver in human.

Material and Methods: This is a Cross-sectional study carried out on dry human sacra to study the anatomical variations of sacral hiatus. Total 80 human sacra were collected from Department of Anatomy. Only dry sacra with complete sacral hiatus were included in this study. Damaged sacra were excluded in this study. For the study various parameters and measurement were used for the study. With the help of naked eye the shape of the sacral hiatus was noted. The length of sacral hiatus was measured from apex to the midpoint of base; the antero-posterior depth of sacral hiatus at the apex was measured with the help of vernier calipers and recorded as data. With the help of vernier caliper the transverse width of sacral hiatus at the base was also measured between the inner aspects of inferior limit of the sacral cornu with the help of divider and then adjusted and calculated.

Result: In this all the sacrum studied was composed of five segments in 80 cases. There were many variations in the shape of sacral hiatus. In 38 (47.5\%) sacra the shape was Inverted-U whereas sacra Inverted V was seen in 21(26.3\%). Both the over sorts were considered as ordinary and the sacral break was show against 4th and 5th sacral sections. The irregular shaped of sacral hiatus was observed in 12(15\%) cases. A "Dumbbell" shaped sacral hiatus was observed in 5(6.3\%) cases with a nodular bony growth projecting medially from both margins. The dorsal wall of sacral canal was entirely absence in $3(3.8 \%)$ cases. a rare phenomenon, absence of sacral hiatus was observed in $1(1.3 \%)$ only.

Conclusion: There was variability in the anatomical structure of the sacral hiatus. The inverted $U$ shape of sacral hiatus was most commonly seen. Apex and base of the hiatus were most commonly seen at the level of S4 and S5 respectively. These estimations will be of colossal esteem in administration of caudal epidural anesthesia and variations in shape and estimate of sacral rest will help in preoperative assessment of patients. There are anatomical varieties within the sacral break, which may relate to the complication to caudal epidural anesthesia. Understanding of these varieties may progress the victory rate of caudal epidural anesthesia.

Keywords: Sacrum, Sacral hiatus, apex, base, caudal epidural anaesthesia 


\section{Introduction}

Sacrum is a triangular bone shaped by combination of five sacral vertebrae. It is embedded as a wedge between the two innominate bones at the upper and back portion of pelvic bone. The opening show at the caudal conclusion of sacral canal is known as sacral rest. It is shaped due to the disappointment of combination of laminae of the fifth (every so often 4th) sacral vertebra. It is situated inferior to the 4th (or 3rd) fused sacral spines or lower end of median sacral crest'. On the surface the hiatus lies about two inches above the hip of coccyx beneath the skin of natal cleft. The structures of Sacrum passing through sacral hiatus are a pair of 5th sacral nerves, a pair of coccygeal nerves, filum terminale externam, which passes to coccyx and fibro-fatty tissue ii.

Sacrum is a vital bone for recognizable proof of sex in human skeletal framework. Since it may be a component of hub skeleton and and pelvic support, it has an applied significance in deciding sexual orientation with the assistance of estimation carried upon it. The wellknown strategy for assurance of male and female sacra has been the Sacral file (SI). iii The varieties within the structure of dorsal divider of sacral canal are various. It may be open all through its whole length or there may be moo lying lamina of to begin with sacral vertebra.

Other varieties incorporate lacks between

its predominant and second-rate limits, pulverization of lumen of sacral canal and hard abundance annihilating the break. The nearness of any gaps may allow the needle to elude the canal coming about in subcutaneous statement of anesthetic operator. ${ }^{\text {iv }}$ The sacral hiatus has been used for administration of caudal epidural anesthesia in obstetrics as well as orthopedic practice for treatment and diagnosis. The foremost visit issue experienced in caudal epidural square is needle situation as in some cases it is troublesome to decide the anatomical area of sacral rest particularly in grown-ups. Clinical assessment of needle arrangement can be done with ultrasonography or fluoroscopy. In any case, it isn't continuously doable to do so since of time and cost limitations. Varieties have been found within the shape and level of sacral break. Anatomical points of interest and the information of real shape and size of sacral rest and its varieties play a major part within the victory of neddle situation ${ }^{\mathrm{v} \text {,vi\&vii }}$.

CEB is broadly utilized in urology, orthopaedics, proctology and common surgery separated from obstetrics for the determination and treatment. Subsequently intensive information of the anatomical highlights within the dorsal locale of sacrum in male and female sex will definitely lead to the decrease within the number of disappointments of the talented clinician within the organization of caudal absense of pain. The show ponder is attempted to clarify the anatomic varieties of sacral break in male and female sex which may offer assistance for making strides the unwavering quality of caudal epidural piece ${ }^{\text {viii }}$. The nearness of abnormally huge rest may demonstrate perilous to life, owing to the chance of puncturing the dural sac and making an intradural infusion.

The total agenesis of the dorsal divider may be one of the uncommon contraindication to CEB since of the plausibility of puncturing the dura ${ }^{i x}$. It is also utilized for three-dimensional color visualization of lumbosacral epidural space ${ }^{x}$. The distal-most parcel of the dural sacends at the level of s2-keeping in intellect the significance of deciding the anatomic area of the SH amid CEB. The equilateral triangle between summit of $\mathrm{SH}$ and superolateral sacral peaks or back predominant iliac spines is certainly of utilize in deciding the area of $\mathrm{SH}$ amid $\mathrm{CEB}^{\mathrm{xi}}$. The main of this study is to find out the anatomical variations of sacral hiatus of the cadaver in human.

\section{Material and Methods:}

This study was carried out in the department of Anatomy Saraswati Medical College and hospital, Unnao. This is a Cross-sectional study carried out on dry human sacra to study the anatomical variations of sacral hiatus. Total 80 human sacra were collected from Department of Anatomy. Only dry sacra with complete sacral hiatus were included in this study. Damaged sacra were excluded in this study. For the study various parameters and measurement were used for the study. With the help of naked eye the shape of the sacral hiatus was noted. The length of sacral hiatus was measured from apex to the midpoint of base; the antero-posterior depth of sacral hiatus at the apex was measured with the help of vernier calipers and recorded as data. With the help of vernier caliper the transverse width of sacral hiatus at the base was also measured between the inner aspects of inferior limit of the sacral cornu with the help of divider and then adjusted and calculated. The data were analysed with the help of SPSS version 15.0.

\section{Result:}

In this all the sacrum studied was composed of five segments in 80 cases. There were many variations in the shape of sacral hiatus and is shown in table 1. In 38 $(47.5 \%)$ sacra the shape was Inverted- $U$ whereas sacra Inverted $V$ was seen in $21(26.3 \%)$.

Both the over sorts were considered as ordinary and the sacral break was show against 4 th and 5 th sacral 
sections. The irregular shaped of sacral hiatus was observed in $12(15 \%)$ cases. A "Dumbbell" shaped sacral hiatus was observed in $5(6.3 \%)$ cases with a nodular bony growth projecting medially from both margins. The dorsal wall of sacral canal was entirely absence in $3(3.8 \%)$ cases. a rare phenomenon, absence of sacral hiatus was observed in $1(1.3 \%)$ only.

Table 1: Showing the shape of sacral hiatus

\begin{tabular}{lll}
\hline Shape & Number & Percentage \\
\hline Inverted- U & 38 & 47.5 \\
\hline Inverted- V & 21 & 26.3 \\
\hline Dumbbell & 5 & 6.3 \\
\hline Irregular & 12 & 15.0 \\
\hline Absence of dorsal wall & 3 & 3.8 \\
\hline Absence of sacral hiatus & 1 & 1.3 \\
\hline Total & 80 & 100 \\
\hline
\end{tabular}

In this study there showed variable between the levels of the apex of $\mathrm{SH}$ and that of base as shown in table no 2 and 3 below. The level of the apex of $\mathrm{SH}$ extended between middle of $3 r d$ to middle of 5 th sacral segments.

Table 2: Showing the level of Apex of Sacral hiatus with respect to level of sacral vertebra

\begin{tabular}{lll}
\hline Level of Apex & Number & Percentage \\
\hline 5th Sacral Vertebra & 3 & 4.1 \\
\hline 4th Sacral Vertebra & 39 & 52.7 \\
\hline 3rd Sacral Vertebra & 32 & 43.2 \\
\hline Total & 74 & 100 \\
\hline
\end{tabular}

Table 3: Showing level of Base of Sacral hiatus with respect to level of sacral vertebra

\begin{tabular}{lll}
\hline Level of Base & Number & Percentage \\
\hline 5th Sacral Vertebra & 66 & 89.2 \\
\hline 4th Sacral Vertebra & 3 & 4.1 \\
\hline 1stcoccyx vertebra & 5 & 6.8 \\
\hline Total & 74 & 100.0 \\
\hline
\end{tabular}

The antero-posterior depth of sacral canal at the apex ranged between $2 \mathrm{~mm}$ to $9 \mathrm{~mm}$

Table 4: Length of Sacral hiatus from apex to midpoint of base

\begin{tabular}{lll}
\hline Length of sacral hiatus $(\mathbf{m m})$ & Number $(\mathbf{n}=\mathbf{7 4})$ & Percentage \\
\hline $0-10$ & 8 & 10.8 \\
\hline $11-20$ & 31 & 41.9 \\
\hline $21-30$ & 21 & 28.4 \\
\hline $31-40$ & 13 & 17.6 \\
\hline $41-50$ & 1 & 1.4 \\
\hline
\end{tabular}

Table 5: Transverse width of sacral hiatus at the base measured between the inner aspect of inferior limit of sacral cornua

\begin{tabular}{lll}
\hline Transverse width $(\mathbf{m m})$ & Number $(\mathbf{n}=\mathbf{7 4})$ & Percentage \\
\hline $0-5$ & 1 & 1.4 \\
\hline $6-10$ & 12 & 16.2 \\
\hline $11-15$ & 45 & 60.8 \\
\hline $16-20$ & 16 & 21.6 \\
\hline
\end{tabular}

Table 6: Antero-posterior depth of sacral canal at the level of apex

\begin{tabular}{lll}
\hline AP depth $(\mathbf{m m})$ & Number $(\mathbf{n = 7 4 )}$ & Percentage \\
\hline $0-3$ & 18 & 24.3 \\
\hline $4-6$ & 46 & 62.2 \\
\hline $7-9$ & 10 & 13.5 \\
\hline
\end{tabular}

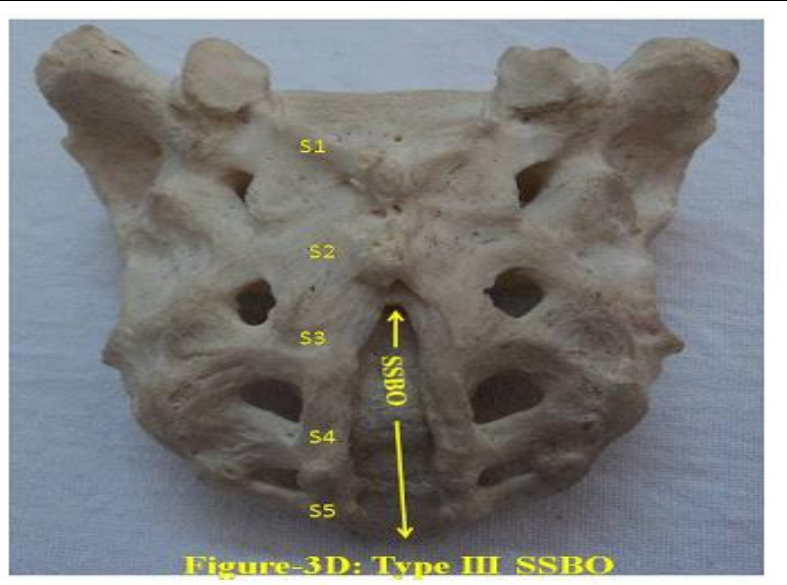

Figure 1: showing Type-III bifida on dorsal surface of sacrum. S1, S2, S3, S4 and S5 show sacral spine1 to spine 5 , SSBO stands for sacral spina bifida occulta.

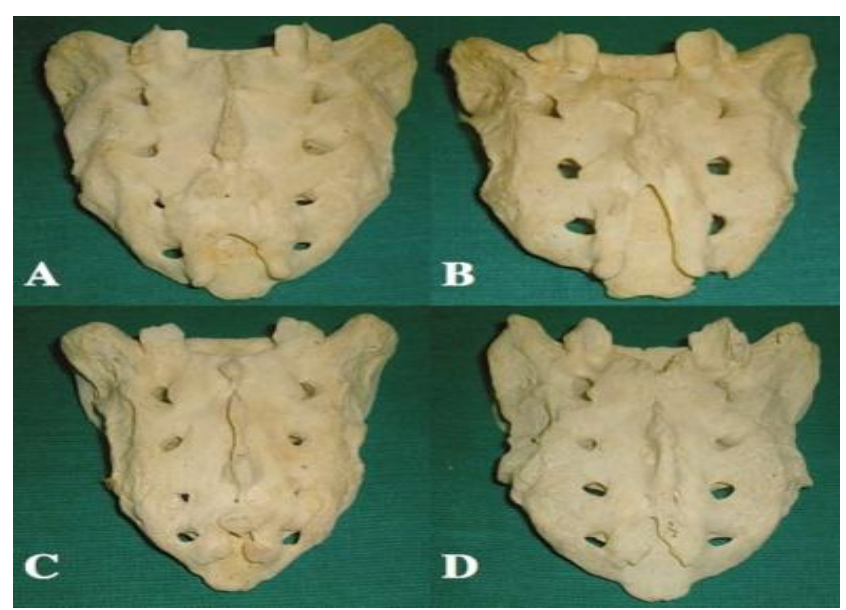

Figure 2: Shape of sacral hiatus. A) Inverted U shaped. B) Inverted V shaped. C) Dumbbell shaped, and D) Irregular shaped. 


\section{Discussion:}

Varieties in anatomical highlights of sacral rest have clinical suggestions in strategy of caudal epidural anesthesia. With this foundation, morphometric think about of sacral break was carried out with reference to population of Maharashtra state of India as geological and racial factors have been seen to influence estimations. Three hundred dry sacra from different therapeutic colleges were included in this think about. Different pertinent measurements of sacral rest were taken and analyzed. The nitty gritty morphometric think about of sacral rest is of incredible pertinence, since this course is regularly utilized for caudal epidural anesthesia in perineal surgery and caudal absense of pain for a effortless conveyance ${ }^{\text {xii }}$.

In this study showed the shapes of sacral hiatus were mostly inverted-U shaped $47.5 \%$ and inverted-V $26.3 \%$ in which both type are consider as normal. Studied of Nagar et $\mathrm{al}^{\mathrm{xiii}}$ and Kumar et $\mathrm{al}^{\mathrm{xiv}}$ showed dumb-bell shape in $13.3 \%$ and $7.43 \%$ cases respectively which showed little bit more than this study. In a studied of Trotter et al ${ }^{\mathrm{xv}}$ showed cases of complete agenesis of sacral hiatus was $1.8 \%$ whereas in this study it was $1.3 \%$. According to the studied of Kiran. V. et al ${ }^{x \mathrm{i}}$ showed 1 sacrum as agenesis of sacral hiatus due to absence of dorsal wall of sacral canal out of 50 sacra (2\%). Suma $H Y$ et al ${ }^{x v i i}$ studied showed out of 150 sacra, inverted $-U$ as $44 \%$, inverted $28.27 \%$, irregular $10.1 \%$, dumbbell $12.3 \%$ and complete spina bifida $5.33 \%$. In this study Length of sacral hiatus varied from $4 \mathrm{~mm}$ to $43 \mathrm{~mm}$ and the arithmetic mean was $19.7 \mathrm{~mm}$ and median was $19.1 \mathrm{~mm}$ and reference range was between 6.7 to $38.6 \mathrm{~mm}$ which showed similar to the study of Kumar $V$ et al. Anteroposterior profundity of sacral canal at pinnacle of sacral break is imperative because it should be adequately huge to confess a needle.

Different diameters leads to subcutaneous testimony of soporific medicate. Within the display consider the antero-posterior profundity extended from 2 to $9 \mathrm{~mm}$ with number-crunching cruel of $4.0 \mathrm{~mm}$ and middle of $4.0 \mathrm{~mm}$ which is similar to the study of Edwards WB et al, Kumar $\mathrm{V}$ et al, Sekiguchi $\mathrm{M}$ et al and Lanier VS et a ${ }^{\text {xviii. }}$. The study of Lanier et $\mathrm{al}^{\mathrm{xix}}$ showed bigger transverse width at base to be $19.3 \mathrm{~mm}$ and Sekiguchi $M$ et al ${ }^{\times x}$ showed a lower arithmetic mean of transverse width to be $10.2 \mathrm{~mm}$ among.

\section{Conclusion:}

There was variability in the anatomical structure of the sacral hiatus. The inverted $U$ shape of sacral hiatus was most commonly seen. Apex and base of the hiatus were most commonly seen at the level of S4 and S5 respectively. These estimations will be of colossal esteem in administration of caudal epidural anesthesia and variations in shape and estimate of sacral rest will help in preoperative assessment of patients. There are anatomical varieties within the sacral break, which may relate to the complication to caudal epidural anesthesia. Understanding of these varieties may progress the victory rate of caudal epidural anesthesia.

\section{Reference:}

1. Standring S. Sacrum. In: Standring S, eds. Grays Anatomy. 39th ed. London: Elsevier Churchill Livingstone; 2005: 749-754.

2. Peter L William et al. Gray's anatomy 38th edition. Churchill Livingston 2000;592-531 and 673-674.

3. Hardlika A. Practical anthropometry. Philadelphia: Winster Institute; 1939. Quoted by Krogman 1962.

4. Trotter M, Letterman GS. Variations of female sacrum: Their significance in continuous caudal anesthesia. Surg Gynecol Obstet. 1944;78(4):41924.

5. Nagar SK. A study of sacral hiatus in dry human sacra. J Anat Soc India 2004;53:18-21.

6. Sekiguchi M, Yabuki S, Satoh K, Kikuchi S. An anatomic study of the sacral hiatus: A basis for successful caudal epidural block. Clin J Pain 2004;20:51-4.

7. Senoglu N, Senoglu M, Oksuz H, Gumusalan $Y$, Yuksel KZ, Zencirci B, et al. Landmarks of the sacral hiatus for caudal epidural block: An anatomical study. Br J Anaesth 2005;95:692-5.

8. Nagar SK. A study of sacral hiatus in dry human sacra. J Anatomic Soc India. 2004;53(2):18-21.

9. Trotter $M$, Letterman GS. Variations of male sacrum: Their significance in continuous caudal anesthesia. Surg Gynecol Obstet. 1944;78(4):41924

10. Saberski L, Kitahata L. Direct visualization of lumbosacral epidural space through the sacral hiatus. Anesth Analg. 1995;80:839-40. [PubMed: 7893046]

11. Kumar V, Soubhagya RN, Bhagatu KP, Thejodhar P. Sacral hiatus in relation to low back pain in South Indian population. Bratisl Lek Listy. 2009;110:43641. [PubMed: 19711833]

12. Edwards WB, Hingson RA. Continuous caudal anaesthesia in obstetrics. American journal of surgery 1942; 57: $459-464$.

13. Nagar SK. A study of sacral hiatus in dry human sacra. Journal of Anatomical Society of India 2004; 53(2): $18-21$. 
14. Kumar $\mathrm{V}$ et al. Morphometrical study of sacral hiatus. Journal of Anatomical society of India 1992; 41(1): $7-13$.

15. Trotter $M$. and Letterman GS. Variations of the female sacrum: Their significance in continuous caudal anaesthesia. Surg. Gynecol. Obstet 1944; 78(4): 419 - 424.

16. Kiran $\mathrm{V}$ et al. Agenesis of dorsal wall of sacral canal. Anatomica karnatka 2011; 5 (1): 69-71.

17. Suma HY et al. A study of sacral hiatus among sacra in south Indian population. Anatomica karnatka 2011; 5 (3): 40-44.

18. Lanier VS, Mcknight HE, Trotter M. Caudal analgesia: An experimental and anatomical study. American journal of Obstetrics and Gynaecology 1944; 47(5): 633 - 641.

19. Lanier VS, Mcknight HE, Trotter M. Caudal analgesia: An experimental and anatomical study. American journal of Obstetrics and Gynaecology 1944; 47(5): 633 - 641.

20. Sekiguchi M, Yabuki S, Satoh K, Kikuchi S. An Anatomical Study of the Sacral Hiatus: A Basis for Successful Caudal Epidural Block. Clinical journal of Pain 2004; 20(1): 51 - 54. 